\title{
Die Sicherungsübereignung im deutschen, englischen und brasilianischen Recht
}

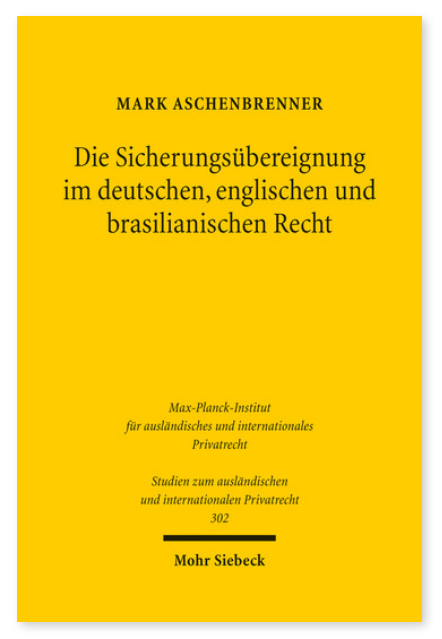

2014. XXX, 380 Seiten. StudIPR 302

ISBN 978-3-16-153157-6

DOI 10.1628/978-3-16-153157-6

eBook PDF 94,00€

ISBN 978-3-16-153156-9

fadengeheftete Broschur 94,00€
Die deutsche Sicherungsübereignung, die englische legal mortgage und die brasilianische alienação fiduciária haben gemeinsam, dass die Vollberechtigung am Sicherungsgegenstand auf den Sicherungsnehmer übertragen wird. In allen drei Rechtsordnungen verursacht dieses Konzept dogmatische und praktische Schwierigkeiten. Mark Aschenbrenner arbeitet die wesensimmanenten Probleme der genannten Vollrechtssicherheiten heraus und überprüft die Lösungsansätze des deutschen, englischen und brasilianischen Rechts. Dazu deckt er zunächst Parallelen in der geschichtlichen Entwicklung und in der Dogmatik der Rechtsinstitute auf und untersucht anschließend die Ausgestaltung der Sicherungsrechte - insbesondere hinsichtlich Zwangsvollstreckung und Insolvenz. Im Ergebnis stellt sich heraus, dass Detailregelungen zu Begründung, Verwertung etc. entscheidender für die Effektivität und die Effizienz einer Vollrechtssicherheit sind als ihre Rechtsnatur.

Mark Aschenbrenner Geboren 1984; Studium der Rechtswissenschaften an der Universität Passau und der Universidade Católica Portuguesa; 2013 Promotion; 2012-2014 Rechtsreferendar im Kammergerichtsbezirk.
Jetzt bestellen:

https://mohrsiebeck.com/buch/die-sicherungsuebereignung-im-deutschen-englischen-und-brasilianischen-recht9783161531576?no_cache=1

order@mohrsiebeck.com

Telefon: +49 (0)7071-923-17

Telefax: +49 (0)7071-51104 